\title{
Laboreal
}

Volume $2 \mathrm{~N}^{\circ} 1$ | 2006

Varia

\section{Entre a experimentação regulada e a experiência vivida : as dimensões subjectivas da actividade do ergónomo em intervenção}

Entre la experimentación regulada y la experiencia vivida : las dimensiones subjetivas de la actividad del ergónomo en intervención

Entre expérimentation réglée et expérience vécue : les dimensions subjectives de l'activité de l'ergonome en intervention

Between regulated experimentation and lived experience : the subjective dimensions of the activity of an ergonomist in action

\section{François Daniellou}

Tradutor. Rita Gil Mata

\section{(2) OpenEdition}

\section{Journals}

\section{Edição electrónica}

URL: http://journals.openedition.org/laboreal/13892

DOI: $10.4000 /$ laboreal. 13892

ISSN: 1646-5237

Editora

Universidade do Porto

\section{Refêrencia eletrónica}

François Daniellou, «Entre a experimentação regulada e a experiência vivida : as dimensões subjectivas da actividade do ergónomo em intervenção », Laboreal [Online], Volume 2 №1 | 2006, posto online no dia 01 julho 2006, consultado o 10 outubro 2019. URL : http:// journals.openedition.org/laboreal/13892 ; DOI : 10.4000/laboreal.13892

\section{Este documento foi criado de forma automática no dia 10 outubro 2019.}

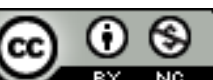

Laboreal está licenciado com uma Licença Creative Commons - Atribuição-NãoComercial 4.0 Internacional. 


\section{Entre a experimentação regulada e a experiência vivida : as dimensões subjectivas da actividade do ergónomo em intervenção}

Entre la experimentación regulada y la experiencia vivida : las dimensiones subjetivas de la actividad del ergónomo en intervención

Entre expérimentation réglée et expérience vécue : les dimensions subjectives de l'activité de l'ergonome en intervention

Between regulated experimentation and lived experience : the subjective dimensions of the activity of an ergonomist in action

\section{François Daniellou}

Tradução : Rita Gil Mata

\section{REFERÊNCIA}

Artigo original : Daniellou, F. (2006). Entre expérimentation réglée et expérience vécue : Les dimensions subjectives de l'activité de l'ergonome en intervention. @ctivités 3 (1), 5-18, http://www.activites.org/v3n1/daniellou.pdf

1 Já há muito tempo que o ergónomo está interessado no trabalho dos outros. Inicialmente, sobre o de operadores de "base", quer sejam operários, empregados, controladores aéreos ou de processos contínuos. Mais recentemente, a actividade dos conceptores, dos organizadores, dos quadros tornaram-se objecto da sua atenção. Mas o ergónomo em si é também um(a) operador(a), pelo que a sua actividade, nomeadamente de intervenção, pode ser analisada. 
2 Lembraremos primeiro alguns aspectos e desafios do desenvolvimento da pesquisa sobre a intervenção ergonómica. Discutiremos depois em que medida os modelos de actividade aplicados ao ergónomo, seguiram o desenvolvimento dos modelos mais gerais da actividade utilizados em ergonomia : o modelo do sujeito-ergónomo não se tornou mais pobre que o modelo do sujeito-operador actualmente utilizado em ergonomia?

3 Argumentaremos a favor de uma maior consideração das dimensões subjectivas da actividade do ergónomo nos modelos que tentam dar conta deste último, nomeadamente ao nível do ensino. Esta necessidade é, certamente, mais ou menos forte de acordo com os tipos de situação nas quais o ergónomo intervém. Limitaremos as nossas propostas às intervenções ergonómicas que se relacionam com a concepção ou a transformação das situações de trabalho.

\section{Modelisar a actividade do ergónomo : um campo de investigação em ergonomia}

4 O interesse de modelisar a actividade transformadora do ergónomo parece agora admitido (Pinsky, 1992 ; Daniellou, 1992, 1996, 1999 ; Falzon, 1997 ; Lamonde, 2000). Considerar a actividade dos ergónomos como objecto de formalização responde a três desafios :

- Trata-se primeiro de melhor elucidar os mecanismos pelos quais os ergónomos contribuem para a transformação das situações de trabalho (Daniellou, 1992). A hipótese antes implícita (como em Guèrin, Laville, Daniellou, Duraffourg \& Kerguelen, 1991, 1997) era de que as suas análises das situações de trabalho e os seus conhecimentos gerais sobre o homem no trabalho, permitiam-lhes desaguar em "recomendações" que seriam postas em prática de modo autónomo pelos actores da empresa em questão. Esta hipótese parece hoje muito fraca para explicar as suas acções, os seus sucessos e os seus contratempos.

- Trata-se depois de pôr à disposição dos profissionais formas de conceptualização que favoreçam a sua reflexão na acção, as discussões entre eles, a gestão de crises e, de um modo mais geral, a elaboração de regras profissionais (Martin \& Baradat, 2003).

- Trata-se enfim de favorecer o ensino e a transmissão da profissão (Lamonde, 2000).

5 Descrevemos em outro lugar (Daniellou, 1999 ; Petit, Querelle \& Daniellou, no prelo), as diferentes metodologias que podiam ser utilizadas para analisar e modelisar a actividade do ergónomo, de acordo com o observador-analista ser ou não membro da equipa de investigação. Lamonde (2000) insiste sobre os diferentes tipos de verbalização que podem ser realizados e sobre as dificuldades que estes comportam.

6 O objecto deste artigo não é, por conseguinte, argumentar novamente sobre o interesse de uma análise da actividade do ergónomo, nomeadamente na intervenção.

7 É sim, de retomar os próprios modelos da actividade que são utilizados para descrever a do ergónomo e avaliar em que medida estes acompanharam o enriquecimento dos modelos do sujeito e da actividade mobilizados em ergonomia. 


\section{Uma evolução dos modelos de actividade}

8 Numa obra recente, Rabardel e Pastré (2005) reuniram um conjunto de contribuições relativas aos "modelos do sujeito para a concepção". Pode-se encontrar no título um remoto eco da célebre questão de Wisner (1971) : "A que homem deve o trabalho ser adaptado?" Entre os dois textos, cujos títulos reflectem sem dúvida a mesma preocupação, um caminho considerável foi percorrido, comportando, claro está, tanto novas dificuldades como vias para a acção ergonómica.

O texto de Wisner tinha um objectivo limitado : recordar a diversidade e a variabilidade das características físicas dos seres humanos, face ao conceito tayloriano de "homemmédio". Não é de nenhum modo representativo do modelo de ser humano de que o seu autor era portador, de quem conhecemos a cultura médica, histórica e social. Mas sublinha o tipo de debates que era necessário fazer avançar há 35 anos atrás.

10 Hoje, o conceito que Rabardel e Pastré julgaram necessário adiantar para aclarar a intervenção em concepção é o de "sujeito". o projecto é explícito : "os trabalhos sobre as dimensões cognitivas da actividade são tão desenvolvidos que acabam por dar uma representação distorcida dos sujeitos humanos. É necessário, no plano da investigação, desenvolver conhecimentos mais equilibrados e representativos do humano [1] (Rabardel, 2005, p. 13). Os autores elaboram o retrato de um "sujeito capaz", em desenvolvimento, que mobiliza um conjunto de recursos internos-externos, mas que não se limita aos recursos de que dispõe: "Mas ocorre uma crise, uma ruptura, e podemos então ver que o sujeito não se pode confundir com a organização da sua actividade : ele é irredutível e insubstituível em relação a ela" (Rabardel \& Pastré, op. cit., p. 4). Pastré (2005a, pp. 231 sqq) trabalhou a noção de "génese" até falar de "génese identitária" para evocar a reconstrução do sujeito quando este "sob o golpe das circunstâncias, não consegue mais reconhecerse no género ou no mundo nos quais ele tinha o hábito de evoluir." (p.259).

11 Esta tomada de posição, a última à data, inscreve-se evidentemente numa longa série de interpelações da ergonomia sobre os modelos de ser humano que ela utiliza quando analisa a sua actividade. Nós tentámos refazer uma parte da história destes alertas (Daniellou, 2005). A psicodinâmica (Dejours, 1981), a ergologia (Schwartz, 2000), a clínica da actividade (Clot, 1999), os trabalhos de Curie (2000), por exemplo, com panos de fundo teóricos diferentes, contribuíram todos para a evolução dos olhares sobre a actividade humana no seio da comunidade da "ergonomia da actividade".

12 Certamente estas diferentes abordagens carregam olhares distintos sobre as potencialidades vitais do sujeito e sobre o que o reprime, ou sobre os laços entre conhecimento do ser humano no trabalho e acção transformadora. Mas não pretendemos aqui descrever as diferenças, às vezes importantes, entre elas. Pretendemos antes retomar que os modelos gerais da actividade humana no trabalho mobilizados hoje em dia em ergonomia integram frequentemente as dimensões seguintes :

1. A actividade não se pode limitar ao "que é posto em prática para realizar as tarefas". A actividade é uma fatia da vida, cujos determinantes i) não estão todos ligados ao trabalho ; ii) não estão todos presentes na janela geográfica e temporal da observação. A actividade encontra os seus motivos e alguns dos seus objectivos no conjunto da história da pessoa, nas suas dimensões profissionais e não-profissionais. É impossível, por exemplo, compreender o custo dos compromissos que um operador trabalhando por turnos faz face aos horários de 
trabalho, se não tivermos entendido "que ele está disposto a fazê-lo até que a sua filha tenha o bacharelato". A multiplicidade dos determinantes não implica que o ergónomo deva explorar o seu conjunto a cada vez, mas antes que ele/ela não pode definir, à priori, o perímetro do que será essencial para compreender uma actividade de trabalho.

2. O conjunto da biografia da pessoa, com os seus aspectos familiares, sociais, culturais, contribuiu para nela estruturar um grupo de valores que o levam a não valorizar de modo equivalente todos os componentes e todos os produtos da sua actividade. Estes valores carregados pela pessoa entram em ressonâcia e em confrontação com as normas e os valores presentes na situação de trabalho. Estas outras "normas antecedentes" (Schwartz, 2000, p.594) provêm, por um lado, da lei, dos regulamentos internos da empresa, dos procedimentos, das instruções, das matérias trabalhadas e ferramentas postas à disposição. Por outro lado, elas foram forjadas pela história dos colectivos de trabalho, das "entidades colectivas relativamente pertinentes" em relação à actividade do sujeito em questão (ibid., p. 604). Finalmente elas provêm ainda em parte dos clientes (ou utentes, pacientes, alunos...)

3. As normas e valores não são espontaneamente compatíveis, pelo contrário, são frequentemente fontes de contradições. O seu tratamento não resulta de uma "optimização", já que elas são de natureza heterogénea e não existe um equivalente geral ao qual elas pudessem corresponder. Por exemplo, Dejours (1995, p. 79) recupera os termos de Habermas para evocar as racionalidades do agir (eficácia no mundo físico, precisão no mundo social, autenticidade no mundo subjectivo) e as deliberações às quais elas dão lugar. Todos os objectivos, que resultam de diferentes racionalidades, nem sempre podem ser atingidos simultaneamente, e Clot (1999) sublinhou que, o que custa no trabalho não é somente o que é feito, mas também o que procuramos fazer sem o conseguir.

4. Assim, cada um é, no trabalho, confrontado com um "debate de normas", entre o "uso de si por si" e o "uso de si pelos outros" (Schwartz, 2000), no qual participa "activamente", ou seja, procurando através da sua actividade influenciar o que daí resultará, ter um papel nas regras que acabarão por prevalecer, a "renormalizar o meio" (Canguilhem, 1966).

5. Estas deliberações sobre os valores contraditórios são constitutivas do ser humano como "sujeito" (Schwartz fala do "corpo-si", Bruner do "self"). As formulações são diferentes... Curie (2000, p. 19) indica que procurou "analisar os processos de personalização, ou seja, as actividades de um indivíduo comportando-se como sujeito pelas suas deliberações sobre valores contraditórios, procedimentos antagónicos, projectos incompatíveis ou contraditórios, e reestruturando, na conclusão provisória destas deliberações, os sistemas internos, cognitivos, conativos e axiológicos organizadores dessas condutas nas situações de conflito". Pastré (2005a, p. 259) escreveu : "Os organizadores da actividade constituem os recursos globais à disposição do sujeito, mas não se confundem com ele. O sujeito dispõe destes recursos ; ele pode até delegar-lhes a orientação da sua acção ; ele pode aumentar os seus recursos ou reorganizá-los quando a necessidade se faz sentir. Mas existem momentos, e os momentos de ruptura criadora são exemplares, onde é preciso admitir que não haveria sujeito sem transcendência relativamente aos organizadores da actividade." Schwartz evoca o "corpo-si", "este corpo, este mesmo corpo, que tenta fazer face a todas as situações de vida, este "si" do uso de si, à prova de todas as circulações entre "trabalho" e "não trabalho", este corpo que liga o sincrónico ao diacrónico, é ao mesmo tempo o corpo biológico, o corpo "biográfico" que carrega os estigmas da sua tentativa de inserção no ser social, o corpo falante e significante, o corpo cultural e histórico (2000, p. 609).

13 Todas estas questões dirigidas ao ergónomo não necessitam certamente que ele/ela mobilize uma modelisação do ser humano no trabalho onde as dimensões subjectivas sejam postas em primeiro plano. Na medida em que os modelos de actividade produzidos pelo ergónomo não visam descrever todas as dimensões da actividade, mas servir de base a transformações pertinentes, é claro que, em muitos casos, ele pode 
melhorar significativamente um ambiente de trabalho com modelos mais reduzidos. Mas o ergónomo não pode nunca prever o nível de modelisação da actividade humana que será necessário pôr em prática para compreender o que está em jogo numa dada situação e transformá-la. Se os trabalhadores se expõem mais aos tóxicos e poderiam não o fazer adoptando uma outra estratégia, é talvez porque, fazendo-o, eles conseguem aumentar o seu salário e portanto melhor financiar os estudos dos seus filhos ; é talvez porque a história do colectivo valoriza as situações de risco como prova de integração, ou talvez ainda porque... As acções transformadoras não serão, sem dúvida, as mesmas em um ou outro caso.

Os modelos classicamente postos em prática em ergonomia combinam em proporções variáveis uma componente biológica (o humano como sistema de tratamento da energia) e uma componente cognitiva (o humano como sistema de tratamento da informação). O quadro "tratamento da energia/tratamento da informação" aparece claramente como demasiado estreito cada vez que, por exemplo, analisamos as actividades de serviço, onde vemos operadores e operadoras frequentemente confrontados com debates de normas, entre o que a empresa deseja propor como serviço e o que eles entendem como a resposta indicada para a situação do cliente (APST, 1992; Petit, 2005). Este modelo é também insuficiente para entender as dificuldades dos quadros que têm de fazer respeitar regras das quais eles não são autores. Muitas outras situações de trabalho necessitam de levar em conta as dimensões culturais, axiológicas e subjectivas da actividade, nomeadamente todas as situações onde o objecto do trabalho são as pessoas.

Parece-nos que se passa o mesmo com a actividade do ergónomo. 0 leitor que releia os cinco pontos acima enunciados e os aplique, não a uma enfermeira ou a um trabalhador de guichet, mas a um(a) ergónomo(a), poderá considerar que eles perdem então toda a sua pertinência? Parece-nos antes que o enriquecimento dos modelos da actividade apela a uma evolução dos modelos de intervenção ergonómica que servem de base, nomeadamente, ao ensino da prática profissional.

\section{Os modelos de intervenção reflectem a actividade do ergónomo ou são instrumentos desta?}

Numerosos trabalhos, já o dissemos, tentam formalizar a actividade do ergónomo na intervenção. Propõem conceptualizações extremamente úteis, das quais vamos procurar precisar o estatuto e os limites.

\subsection{Estatuto das modelisações de intervenção}

Uma das modelisações da intervenção conhecidas é a que fez Wisner, de modo sintético em "O diagnóstico em ergonomia" (1972, p. 96 sqq), depois em maior detalhe no seu curso (1979). Este modelo foi seguidamente retomado e esclarecido em (Guérin et al., 1991). É descrito um caminho de análise, do pedido ao diagnóstico, passando pela análise ergonómica do trabalho em situações convenientemente escolhidas.

Mais tarde, modelisações foram propostas para a intervenção em projectos industriais (Daniellou, 1985 ; Daniellou \& Garrigou, 1992), em projectos arquitecturais (Martin, 2000), em projectos informáticos. 

tipicamente este: participar na elaboração de conceptualizações (da actividade de intervenção) que favoreçam o desenvolvimento de esquemas profissionais adaptáveis a uma diversidade de situações. Em matéria de condução de projectos industriais, por exemplo, nenhum projecto se desenvolve desde o início ao fim segundo o esquema teórico que foi feito, por causa de ressaltos inevitáveis (Jackson, 1998). Todavia, as invariantes "implementação das estruturas de condução do projecto", "análise de situações de referência", "recenseamento das situações de acção características", "simulações", encontram-se num grande número de relatos de intervenção, ainda que muito diferentes uns dos outros[ $\left.{ }^{3}\right]$.

Portanto, a relação do ergónomo-aprendente com os modelos de intervenção que lhe são propostos não nos parece ser simplesmente uma relação de submissão a uma prescrição. Parecenos que podemos descrevê-la melhor como uma "génese instrumental" (Rabardel, 1995), a modelisação tendo estatuto de um artefacto, que vai ser objecto do desenvolvimento de esquemas no aprendiz. Mas o artefacto em si mesmo vai ser "posto à medida da sua mão" pelo interventor, que vai modificá-lo para melhor dele se servir. 
25 Esta génese instrumental tem lugar, primeiro, na actividade de cada professor. 0 célebre esquema de Leplat e Cuny (1997, p. 55), que se tornou seguidamente o "esquema em cinco quadrados", é um instrumento para o professor, ou seja, a sua utilização é objecto do desenvolvimento de esquemas pessoais (construção progressiva, comentários). Seria extremamente interessante comparar as utilizações que são feitas deste esquema em diferentes lugares de formação.

Esta génese instrumental tem lugar também em cada ergónomo em formação, que se apropria das formalizações que lhe são propostas nas situações, por exemplo de estágio, que ele/ela é levado a viver. Ela continua ainda ao longo de toda a sua carreira profissional. "São os obstáculos, as discordâncias, os conflitos objectivos, subjectivos ou intersubjectivos encontrados na actividade que geram uma intensidade mais ou menos forte de tensão, e que convidam o sujeito a mobilizar e desenvolver as invariantes." (Béguin \& Clot, 2004, p. 45).

27 Mas - e não é o caso de todas as profissões - a comunidade ergonómica "da actividade" muniu-se também dos meios de uma génese instrumental parcialmente colectiva. Alguns colóquios ou congressos visam assim debater explicitamente de novo, trabalhar as conceptualizações da prática, para que elas sejam o mais apropriadas possível (Martins \& Baradat, 2003).

28 As conceptualizações de uma época são discutidas, afinadas, por vezes modificadas ou contraditas, no domínio público, e as suas evoluções são objecto de publicações. Podemos notar, por exemplo, as evoluções consideráveis sobre o estatuto da participação dos trabalhadores na intervenção (Pilnière \& Lhospital, 1998).

29 Longe de uma démarche prédefinida que importa aplicar, os modelos de actividade do ergónomo visam assim permitir a construção de invariantes organizadoras de uma actividade extremamente variada em ambientes diferentes. A questão não nos parece, portanto, saber se os modelos existentes hoje em dia representam fielmente a prática (certamente que não), mas em que medida eles apoiam de modo útil a sua construção, ou, ao contrário, se provocam entraves ao seu desenvolvimento. o desafio em ergonomia não é de aperfeiçoar os modelos para que sejam mais fiéis, mas para que sejam mais operantes (Wisner, 1972).

\subsection{Modelos do operador-ergónomo}

30 Já acima mostrámos a importância que a ergonomia acaba por atribuir às dimensões subjectivas na modelisação da actividade de certas categorias de operadores, particularmente, mas não só, nas actividades de serviço. Ora, só podemos constatar que a maior parte dos modelos de intervenção ergonómica fazem do ergónomo um ser sócio-cognitivo, no sentido que as dimensões físicas, por um lado, e subjectivas, por outro, da sua actividade, são pouco evocadas.

31 Conceptualizações como as da "análise do pedido", do "diagnóstico", da "conduta do projecto", definem para cada componente da intervenção os seus objectivos, uma organização da procura de informação, as regras de acção e de cooperação, as ferramentas mobilizáveis, etc. Elas estão ao serviço das construções cognitivas do ergónomo, das suas tomadas de decisão quanto a operações a efectuar na intervenção.

Além disso, nas modelisações habituais em "ergonomia da actividade", o contexto da acção considerado é, a um nível mais ou menos preciso, um contexto social, multi- 
actores, multi-lógicas, com referências implícitas a descrições sociológicas mais ou menos ricas. Admite-se (nesta comunidade) que a cognição do ergónomo é posta em prática num contexto social. Mas as relações intersubjectivas do ergónomo com os outros actores, as deliberações com as quais ele/ela é confrontado, as racionalidades que ele/ela utiliza na acção, os custos que esta representa para ele/ela, são objecto de poucas formalizações.

Poderíamos parafrasear a frase de Rabardel acima citada: os trabalhos sobre as dimensões cognitivas da actividade do ergónomo são tão maioritários que poderiam acabar por dar uma representação distorcida da prática profissional. Não há aqui um deficit que ganharia em ser corrigido, se quiséssemos melhor preparar os futuros ergónomos para a sua profissão?

Porque outras profissões já o constataram. As dificuldades de professores do ensino secundário, de trabalhadores sociais, de médicos de clínica geral (Davezies \& Daniellou, 2004) são às vezes sérias, com riscos importantes para a sua saúde. Estão nomeadamente ligadas a cursos de formação orientados para o desenvolvimento da sua actividade cognitiva, mas de pouca utilidade para as relações intersubjectivas e os debates de normas com os quais a prática os confronta. As gerações anteriores de ergónomos provinham maioritariamente da reconversão profissional de médicos, psicólogos, sindicalistas, quadros, que tinham tido ocasião, na sua carreira anterior, de construir competências nestes domínios. As gerações actuais qualificam-se na ergonomia principalmente pela formação inicial. É da responsabilidade da profissão, e dos lugares de formação, de os preparar o melhor possível para as experiências que a sua profissão os vai levar a viver.

\section{A intervenção entre experimentação e experiência}

Schwartz (1994) lembrava-o no congresso da SELF. Toda e qualquer situação de trabalho tem a dupla dimensão de uma experimentação regulada e de uma experiência vivida: "qualquer actividade industriosa é sempre, por um lado análoga a uma experimentação, por outro lado experiência ou "encontro" :

- Experimentação regulada porque a situação de trabalho foi previamente concebida, planificada, muitas das suas dimensões foram antecipadas, objecto de protocolos mais ou menos precisos. "Mesmo sendo um ideal, trabalhar sobre e com os conceitos exige esta estandardização dos protocolos" (ibid. p. 540);

- Mas também experiência vivida porque as antecipações que foram feitas não esgotam nunca as variabilidades com as quais se vai confrontar a actividade. São pessoas particulares, colectivos específicos, com a sua história própria, que vão, não realizar, mas cumprir (Hubault, 1996) o que há a fazer. "Dizer que a actividade industrial é sempre reencontro, é lembrar que é impensável, que é absurdo, imaginar neutralizar todas as variáveis singulares" (Schwartz, op. cit., p. 541).

Schwartz exprimiu-se, num congresso sobre "ergonomia e engenharia", para recordar que o que é evidentemente verdade para os conceptores também o é para todos os operadores : reconfigurar, resingularizar o lugar da actividade é como "uma vocação humana" (p. 543). Ele defendia a organização do "encontro", em todas as etapas da concepção, entre os que são portadores da abstracção, dos conceitos generalizadores, e os que são portadores das micro-gestões da variabilidade quotidiana. 
37 Nós defendemos a ideia de que a actividade do ergónomo em intervenção pode ser objecto do mesmo raciocínio. Por um lado, a intervenção é uma experimentação construída pelo ergónomo com os outros actores. Os conhecimentos, os modelos, permitem antecipar certas dimensões desta experimentação, por exemplo nas precauções a ter na redacção de contratos, os tipos de associação dos representantes do pessoal, a estruturação das relações entre dono de obra e empreiteiro... Felizmente o ergónomo não parte do nada, e as formalizações anteriores permitem antecipar alguns objectivos intermediários, orientar certas tomadas de informação (de pôr em posição os bons captores), de prever certos resultados.

Mas, evidentemente, o desenrolar real da intervenção está longe de ser redutível à utilização de um protocolo. 0 ergónomo particular em questão vai desempenhar uma actividade pessoal que ultrapassa largamente o uso de uma metodologia definida previamente. Ele/ela vai ser confrontado com todas as singularidades de uma situação, de pessoas, colectivos, processos técnicos que a compõem, dos elementos de um contexto. Fazendo isto, ele/ela mobiliza-se enquanto pessoa, (que tem também uma vida privada), que tem relações intersubjectivas com os seus interlocutores e é confrontado com deliberações por vezes difíceis, entre interesses contraditórios. A intervenção é também experiência vivida.

As dimensões subjectivas da actividade de intervenção não são, com certeza, negada pelos autores que modelizam a actividade do ergónomo. Mas elas são pouco tematizadas, quer pela disciplina ou pela profissão, como se consistissem numa alquimia privada que não resulta de uma formalização nem de um debate.

Portanto, se seguirmos Cerf e Falzon (2005, p. 15), que propõem considerar que uma caracterização possível da actividade do ergónomo é dizer que se trata de uma actividade de serviço [4], o mínimo é mobilizar para a sua descrição modelos tão ricos quanto os que são correntemente utilizados para compreender o trabalho dos serviços.

\section{0 ergónomo-sujeito e os debates de normas}

41 Os modelos da actividade do ergónomo, que têm vocação para ser "ensináveis" (no sentido de Le Moigne, 1995), parecer-nosiam dever ter em conta pelo menos três aspectos complementares :

1. O tecido social de uma empresa não é feito de interlocutores "típicos" (Schtuz, 1987) : os directores do estabelecimento, representantes do pessoal, conceptores, médicos do trabalho, etc., que o ergónomo encontra na intervenção, têm certas funções definidas pelos quadros e regras que o ergónomo deve conhecer. Mas são também pessoas particulares, que não podem ser reduzidas às simples características da sua função. 0 seu interesse pelas questões de trabalho, de saúde, e as margens de manobra que eles procuram ter nos seus domínios estão ligados à sua história pessoal, familiar, social, e aos valores que daí resultam, tanto quanto às responsabilidades que lhes são confiadas num dado momento. Estes estão todos colocados em debates de normas fortemente personalizados.

2. Se, evidentemente, não é papel do ergónomo reconstruir estas biografias, o resultado da intervenção dependerá largamente da ressonância entre as acções que ele/ela proporá e as preocupações profissionais personalizadas dos seus interlocutores. Deste modo, a metodologia de intervenção ergonómica não pode fundar-se unicamente sobre os actos públicos do ergónomo (aquando das observações, nos grupos de trabalho, de pilotagem...). Nós próprios, nos anos 1985, contribuímos para a difusão de uma formalização de intervenção onde a ênfase se situava excessivamente sobre a realização de diferentes tipos 
de grupo, cuidadosamente equilibrados do ponto de vista da representação dos actores sociais. É um dos méritos de Christol (ver por exemplo, Escouteloup, 2004) ter insistido sobre a dimensão dos "colóquios singulares", entre o ergónomo e os seus interlocutores, de forma individual, como componente essencial da intervenção. Uma visão das relações sociais na empresa que excluiria toda a dimensão intersubjectiva seria assim tão pouco pertinente para o ergónomo quanto para descrever os processos de negociação entre direcção e representantes do pessoal (Dugué, 2005).

3. O ergónomo é, como todo o trabalhador, submetido a debates de normas. Ele/ela o está provavelmente, num grau elevado, na medida em que a sua acção o coloca no centro de tensões entre saúde e formas de eficácia, à articulação entre unicidade da concepção e variabilidades do trabalho quotidiano, em contacto com numerosos actores, sendo cada um portador de dimensões contraditórias da performance da empresa, e situando as suas acções em "mundos" diferentes (Béguin, 2005). A sobrevivência económica é um desafio tão respeitável como a prevenção de problemas musculo-esqueléticos, e o ergónomo não pode preocupar-se com um sem se interessar pelo outro. 0 vigor dos debates de normas com os quais o ergónomo é confrontado, depende certamente de classes de situações nas quais ele/ ela intervém. A concepção de sistemas automatizados, onde a produtividade não é proporcional às operações realizadas pelos humanos, permite por vezes conciliar de forma relativamente harmoniosa os desafios de saúde e de eficácia. As intervenções relativas ao trabalho em cadeia, aos problemas musculo-esqueléticos, aos centros de chamada, lançam frequentemente o ergónomo para o centro de tensões bem mais vivas.

42 Estes debates de normas, entre o "uso de si por si" e o "uso de si pelos outros", em que o ergónomo é actor, não são, de resto, unicamente o reflexo daqueles que existem na empresa. Ele/ela tem também uma história, uma família, uma vida pessoal, que solicitam a sua energia e disponibilidade. Ele/ela intervém num quadro profissional que comporta constrangimentos económicos e que impõe uma legibilidade da sua acção face aos seus colegas.

Esta mobilização subjectiva do ergónomo pode, evidentemente, ser gratificante e contribuir para a sua própria saúde. Mas este resultado favorável dos debates de normas não é dado previamente e o ergónomo pode também correr riscos pessoais no caso contrário.

Esta é a razão pela qual as relações intersubjectivas e as deliberações são uma das componentes da prática profissional, pelas quais as conceptualizações pertinentes, como também a colocação em situações apropriadas, desde o estado da formação inicial, podem ajudar a uma construção mais rápida e menos dificultada das práticas de cada um.

\section{Domínios de investigação e de acção}

Estas proposições, se queremos segui-las, abrem-se para campos de investigação, de práticas de ensino e de debates profissionais.

\subsection{A investigação sobre as dimensões subjectivas na intervenção}

A evolução dos modelos gerais da actividade utilizados em ergonomia, no sentido de uma melhor consideração das dimensões subjectivas, abre caminho para um enriquecimento dos modelos da actividade do ergónomo. 
47 É possível descrever melhor algumas das dimensões subjectivas em jogo na intervenção referenciando, nomeadamente, os trabalhos levados a cabo a propósito de outras profissões. Já sublinhámos, por exemplo, (Daniellou, 1992, p. 116 sqq) o interesse para o assunto dos trabalhos de Balint (1957) sobre os médicos de clínica geral e de Devereux (1967) sobre os etnólogos. Numerosos estudos mais recentes sobre outras profissões poderiam certamente ser proveitosos.

Como o médico, o ergónomo entende um pedido que manifesta a necessidade de recorrer a um terceiro. Este pedido é acompanhado de uma "oferta de representação" do problema, que ele/ ela não pode considerar literalmente. Ele/ela vai oferecer meios para construir o problema em conjunto com quem o apresenta. Esta interacção é susceptível de entrar em ressonância com numerosas dimensões da biografia do ergónomo, quer para o melhor ou para o pior.

49 Como o etnólogo, o ergónomo deve identificar o papel que o fazem representar e considerar que o que ele/ela observa não é independente da sua presença. A cultura e os interesses do ergónomo levam-no a privilegiar certos aspectos da situação sobre a qual ele/ela intervém. Aquilo que ele/ela constata na empresa pode ser fortemente ansiogénico e provocar o desenvolvimento de defesas psíquicas, que afectam a condução da aç̧ão.

50 Tais fenómenos poderiam certamente ser analisados na prática ergonómica. Isto necessitaria que o analista, por exemplo o investigador que tenta modelisar a prática, desse uma atenção particular a certas dimensões da actividade do interventor: os "colóquios singulares" do ergónomo com os seus interlocutores, os debates no interior da equipa de interventores (Jackson, 1998), as discussões com os pares, as graças trocadas entre colegas, ou as formas de brincar com os interventores caloiros. Isto suporia também que o analista, como o faria com todos os outros operadores, interrogasse o ergónomo sobre as formas de custos pessoais que ele/ela sente numa dada intervenção ou na configuração global das intervenções simultâneas. Os recursos que o ergónomo percepciona como disponíveis para o ajudar nas situações difíceis poderiam assim ser descritos.

\subsection{A preparação nas dimensões intersubjectivas da prática}

51 Sem esperar o resultado de tais investigações e de modelisações mais precisas dos debates de normas com os quais o ergónomo se confronta na intervenção, é daqui por diante possível introduzir no ensino uma conceptualização destas dimensões aproveitando os modelos construídos noutros contextos.

52 Na nossa prática de ensino, tentamos contribuir neste sentido com os seguintes ingredientes :

- Uma familiarização dos ergónomos em formação com os quadros conceptuais das disciplinas próximas que esclareçam as dimensões subjectivas de toda a actividade de trabalho (já citamos a psicodinâmica, a ergologia, a clínica da actividade, sendo sem dúvida necessário acrescentar as teorias do stress, a psicologia da saúde, etc.).

- De um modo mais geral, uma procura e análise dos trabalhos que sublinhem as dimensões intersubejctivas de comunicação. Muitos ergónomos em formação manifestaram o seu interesse quando descobriram, ao ler, Watslawick (por exemplo, 1986 e de uma forma mais geral a Escola de Palo Alto), ou Devereux (op.cit.). Os trabalhos de Mauss sobre o talento e o contra-talento (Godbout, 2000)[5], que se revelam particularmente úteis para analisar as 
dificuldades dos médicos de clínica geral (Davezies \& Daniellou, 2004), têm também grande pertinência para a prática reflexiva dos ergónomos.

- Uma evocação, na formação, dos debates com os quais o ergónomo se confronta e as diferentes dificuldades que lhe trouxeram[ $\left.{ }^{6}\right]$. As referências deontológicas conhecidas, e os seus limites, podem ser discutidos. As maneiras de estar dos professores ou dos ergónomosséniores podem ser organizadas para ajudarem em tempo real os ergónomos em formação submetidos a debates difíceis na prática[ $\left.{ }^{7}\right]$.

- Uma complexificação da modelisação das relações sociais. A visão de uma empresa harmoniosa, onde impera um misterioso interesse global, é tão inapropriada como a descrição simplista da oposição de duas forças em presença tal como a dos "assalariados" e a da "direcção". Os desenvolvimentos teóricos em sociologia, por exemplo à volta de JeanDaniel Reynaud (1995, Terssac de, 2003), permitem obter uma imagem de um grande número de forças em presença em toda a organização, e das regulações múltiplas que aí se desenvolvem. É preciso, provavelmente, para a formação dos ergónomos, acrescentar uma reflexão sobre a interacção das dimensões subjectivas e sociais, especialmente nas relações sociais da empresa.

- Uma reflexão sobre o estatuto das regras no trabalho, e mais genericamente no funcionamento dos colectivos. Trata-se principalmente de preparar os ergónomos para uma análise benevolente do trabalho do pessoal de chefia e de lhes evitar confundir abusivamente o exercício normal da autoridade hierárquica com uma conduta perversa.

Não se trata senão de alguns exemplos, uma vez que o que está em jogo é a aplicação, para a compreensão da actividade do ergónomo, do conjunto dos trabalhos em Ciências Humanas. Homenageando o seu mestre, Philippe Malrieu, Curie (2000, p. 7-8) escreve : "À partida, é posta a afirmação que o papel do conhecimento é permitir aos homens participar na construção da sua própria humanidade. Esta construção é considerada como superando as divisões no interior de si mesmo, divisões que resultam da adesão a modelos cujo antagonismo é mais frequentemente mascarado. Esta superação pressupõe por um lado a aquisição de instrumentos intelectuais elaborados pelo homem ao longo da sua história [...], por outro lado, pela inserção em relações interpessoais diversificadas, e finalmente pela possibilidade que os homens têm em utilizar práticas nas quais se expressam as conquistas de autonomia que puderam fazer na sua experiência pessoal. O que para o sujeito dá valor ao acto, não é a sua conformidade às necessidade provenientes de uma qualquer natureza biológica programada ou a modelos sociais, que efectivamente lhe pré-existem, é a participação deste acto na superação das contradições que existem no interior entre estas duas ordens de determinantes [...]. O papel do psicólogo, investigador ou profissional, é de fornecer uma ajuda a este trabalho de si sobre si, pondo em evidência o que o bloqueia e dando sugestões para agir sobre esses obstáculos". Aqui também, parece-nos fácil reler esta citação aplicando-a ao ergónomo como sujeito.

\section{Conclusões}

Uma melhor consideração das dimensões subjectivas da actividade do ergónomo parece-nos necessária desde a formação dos futuros intervenientes. Ela supõe que estas dimensões têm direito ao estatuto científico, ou seja, que os modelos da actividade do ergónomo que têm a dignidade de "referência legítima", as integrem progressivamente. A evolução das teorias da actividade parece-nos preparar esta abertura. 

formado para perceber as dimensões subjectivas da sua própria actividade e para as gerir, o ergónomo estará sem dúvida melhor equipado para compreender e levar em conta os debates de normas nos seus interlocutores e para desenvolver intervenções (ainda) mais pertinentes.

56 Uma defesa, clássica em numerosas profissões, quer que "um bom profissional não tenha problemas, ou, se os tem, que os resolva sozinho". Pôr no colectivo os debates de normas com os quais cada um é confrontado não se pode desenvolver num tal ponto de partida. A multiplicação dos espaços de troca entre ergónomos, sob a forma de debates acerca da prática, regionais ou temáticos, pode ser uma oportunidade para esta consideração das dimensões subjectivas da intervenção, e para a construção de saberes colectivos que permitam melhor situar-se. Uma tal via não é, no entanto, traçada de antemão: entre estados de alma privados, cujo debate colectivo seria obsceno, e dimensões insubstituíveis da prática da profissão e da sua eficácia, o estatuto profissional e científico das deliberações dos ergónomos continua em construção.

\section{BIBLIOGRAFIA}

APST (1992). L'évaluation économique à l'épreuve des services : l'activité entre efficacité et efficience. Rapport de recherche pour le Ministère de la recherche et de la technologie, Aix-enProvence : Université de Provence.

Balint, M. (1957 [1988]). Le médecin, son malade et la maladie. Paris : Payot.

Béguin, P. (2005). Concevoir pour les genèses professionnelles. In P. Rabardel, \& P. Pastré (Eds), Modèles du sujet pour la conception (pp. 31-52). Toulouse : Octarès Editions.

Béguin, P. \& Clot, Y. (2004). L'action située dans le développement de l'activité. @ctivités, 1 (2), 35-49. http://www.activites.org.

Bruner, J.,(1990 [1991]). ...car la culture donne forme à l'esprit. Paris : Eshel.

Canguilhem, G. (1966). Le normal et le pathologique. Paris : PUF.

Cerf, M., \& Falzon, P. (2005). Situations de service : travailler dans l'interaction. Paris : PUF, collection Le Travail Humain.

Clot, Y. (1999). Le travail sans l'homme ? Pour une psychologie des milieux de travail et de vie. Paris : La Découverte.

Curie, J. (2000). Travail, personnalisation, changements sociaux. Toulouse : Octarès Editions

Daniellou, F. (1985). Ergonomie et projets industriels. Cours polycopié, Paris : CNAM Laboratoire d'Ergonomie.

Daniellou, F. (1992). Le statut de la pratique et des connaissances dans l'intervention ergonomique de conception. Thèse d'Habilitation à Diriger des recherches. Éditions du 
Laboratoire d'Ergonomie des Systèmes Complexe, Université Victor Segalen Bordeaux2, Bordeaux.

Daniellou, F. (1996). Questions épistémologiques soulevées par l'ergonomie de conception. In F. Daniellou (Ed.), L'ergonomie en quête de ses principes (pp. 183-200). Toulouse : Octarès Éditions.

Daniellou, F. (1999). The ergonomist is a worker? That is the (epistemological) question. In N. Marmaras (Ed.), Strengths and weaknesses, threats and opportunities of ergonomics in front of 2000 (pp. 2128). Athens : The Hellenic ergonomics society.

Daniellou, F. (2005). The French-speaking ergonomists' approach to work activity : cross influences of field intervention and conceptual models. Theoretical Issues in Ergonomics Science, 6 (5), 409-427.

Daniellou, F., \& Garrigou, A. (1992). Human Factors in design : sociotechnics or ergonomics. In M. Helander, \& M. Nagamachi (Eds.), Design for manufacturability (pp. 55-63). Londres : Taylor and Francis.

Davezies, Ph., \& Daniellou, F. (2004). L'épuisement professionnel des médecins généralistes, une étude compréhensive en Poitou-Charentes. Poitiers : Union Régionale des Médecins Libéraux. http://www.urml-pc/Client/Publications_urml.asp

Dejours, C. (1981[1993]). Travail, usure mentale. Paris : Bayard.

Dejours, C. (1995). Le Facteur Humain. Paris : PUF, collection Que saisje?

Devereux, G. (1967[1980]). De l'angoisse à la méthode dans les sciences du comportement. Paris : Flammarion, collection Nouvelle Bibliothèque Scientifique.

Dugué, B. (2005). Le travail de négociation. Toulouse : Octarès Éditions.

Escouteloup, J. (Ed.) (2004). Trajectoires d'ergonomes : Jacques Christol, Antoine Laville, Yvon Quéinnec. Bordeaux : Laboratoire d'Ergonomie des Systèmes Complexes, Université Victor Segalen Bordeaux 2

Falzon, P. (1997). La construction des connaissances en ergonomie : éléments d'épistémologie. In Actes du XXXIIe Congrès de la SELF (pp. 641-654). Lyon, France.

Godbout, J.T. (2000). Le don, la dette et l'identité. Paris : La Découverte/ M.A.U.S.S.

Guérin, F., Laville, A., Daniellou, F., Duraffourg, J., \& Kerguelen, A. (1991, 1997). Comprendre le travail pour le transformer. Lyon : Éditions ANACT.

Hubault, F. (1996). De quoi l'ergonomie peut-elle faire l'analyse ? In F. Daniellou (Ed.), L'ergonomie en quête de ses principes (pp. 103140). Toulouse : Octarès Éditions.

Jackson, J.M. (1998). Entre situations de gestion et situations de délibération : l'action de l'ergonome dans les projets industriels. Thèse de Doctorat. Éditions du Laboratoire d'Ergonomie des Systèmes Complexes, Université Victor Segalen Bordeaux2, Bordeaux.

Lamonde F. (2000). L'intervention ergonomique, un regard sur la pratique professionnelle. Toulouse : Octarès Éditions.

Le Moigne, J.L. (1995). Les épistémologies constructivistes. Paris : PUF, collection Que sais-je?

Leplat, J., \& Cuny, X. (1977). Introduction à la psychologie du travail. Paris : PUF.

Martin, C. (2000). Maîtrise d'ouvrage, maîtrise d'œuvre, construire un vrai dialogue : la contribution de l'ergonome à la conduite de projets architectural. Toulouse : Octarès Éditions.

Martin C., \& Baradat D. (2003). Des pratiques en réflexion. Toulouse : Octarès Éditions. 
Pastré, P. (2005a). Genèse et identité. In P. Rabardel, \& P. Pastré (Eds.), Modèles du sujet pour la conception (pp. 231-260). Toulouse : Octarès Éditions.

Pastré, P. (2005b). La conception de situations didactiques à la lumière de la théorie de la conceptualisation dans l'action. In P. Rabardel, \& P. Pastré (Eds.), Modèles du sujet pour la conception (pp. 231260). Toulouse : Octarès Éditions.

Petit, J. (2005). Organiser la continuité du service : intervention sur l'organisation d'une mutuelle de santé. Thèse de doctorat d'ergonomie. Université Victor Segalen Bordeaux 2, Bordeaux.

Petit, J., Querelle, L., \& Daniellou, F. (à paraître). Quelles données pour la recherche sur la pratique de l'ergonome? Le Travail Humain (à paraître).

Pilnière, V., \& Lhospital, O. (Eds.) (1998). Participation, représentation, décisions dans l'intervention ergonomique. In Actes des Journées de Bordeaux sur la pratique de l'ergonomie. Université Victor Segalen Bordeaux 2. Bordeaux, France.

Pinsky L. (1992). Concevoir pour l'action et la communication : essai d'ergonomie cognitive. Berne : Peter Lang.

Rabardel, P. (1995). Les hommes et les technologies. Paris : Armand Colin.

Rabardel, P. (2005). Instrument subjectif et développement du pouvoir d'agir. In P. Rabardel, \& P. Pastré (Eds.), Modèles du sujet pour la conception (pp. 11-30). Toulouse : Octarès Editions.

Rabardel, P., \& Pastré, P. (Eds.) (2005). Modèles du sujet pour la conception. Toulouse : Octarès Editions.

Reynaud, J.D. (1995). Le conflit, la négociation et la règle. Toulouse : Octarès Éditions.

Schutz, A. (1987). Le chercheur et le quotidien. Paris : Méridiens Klincksieck.

Schwartz, Y. (1994[2000]). Conférence inaugurale du 29ème congrès de la SELF. In Y. Schwartz (Ed.), Le paradigme ergologique ou un métier de philosophe (pp. 537-548). Toulouse : Octarès Éditions.

Schwartz, Y. (2000). Le paradigme ergologique ou un métier de philosophe. Toulouse : Octarès Éditions.

Terssac, G. de (Ed.) (2003). La théorie de la régulation sociale de JeanDaniel Reynaud. Paris : La Découverte.

Vergnaud, G . (1996). Au fond de l'action, la conceptualisation. In J.M. Barbier (Ed.), Savoirs théoriques et savoirs d'action (pp. 275-292). Paris : PUF.

Watzlawick, P. (1986[1988]). Comment réussir à échouer. Paris : Seuil. Wisner, A. (1971[1995]). A quel homme le travail doit-il être adapté ? In

A. Wisner (1995), Réflexions sur l'ergonomie (1962-1995) (pp. 4756). Toulouse : Octarès Éditions.

Wisner, A. (1972[1995]). Le diagnostic en ergonomie ou le choix des modèles opérants, pp 79-102, In A. Wisner (1995). Réflexions sur l'ergonomie (1962-1995) (pp. 79-102). Toulouse : Octarès Éditions.

Wisner, A. (1979). Analyse de la situation de travail, méthodes et techniques. Cours B3, Paris : Laboratoire d'Ergonomie du CNAM. 


\section{NOTAS}

1. O alerta em relação à ênfase exclusivamente posta sobre as dimensões cognitivas não é, evidentemente, novo. J. Bruner, um dos pais da "revolução cognitiva" já terá por exemplo contribuído ele mesmo, publicando já em 1990 “...porque a cultura dá forma ao espírito”. (Bruner, 1990).

2. E muitos outros onde, quaisquer que sejam as precauções tomadas pelos professores, os estudantes atribuem a estas modelisações um estatuto normativo.

3. Uma questão difícil é a de saber se se trata simplesmente de invariantes dos relatos, ou se se trata verdadeiramente de invariantes das intervenções em si. Béguin e Clot (2004) dizem a propósito dos "planos" de Suchman: "o plano seja um recurso (quando é produzido antes da acção), e tem um papel de orientação da acção, [...] seja um produto à posteriori, uma reconstrução sui generis que visa ter a acção como objecto de reflexão depois da sua efectuação." Esta dupla perspectiva vale para as invariantes da intervenção ergonómica. A análise dos raciocínios no decorrer da intervenção seria necessária para resolver esta questão.

4. Fazemos igualmente referência à tese, ainda no prelo, de Léonard Querelle sobre este tema.

5. Aquele que dá mais do que recebe cria uma dívida no donatário, de facto uma obrigação, e então, de uma certa maneira, domina-o. Mauss estudou nos Maoris o fenómeno pelo qual aquele que recebe fica invadido pelo espírito do dador. Nos Romanos, o devedor que não possa pagar a sua dívida tornava-se escravo do seu credor.

6. Sou sempre surpreendido pela importância que tem, para os ergónomos em formação, o facto que lhes ensinam que os ergónomos experimentados têm pesadelos relativamente às suas próprias intervenções.

7. Jacques Christol (com. pess.) formaliza esta ideia que designa por "SOS Amizade Ergonomia" insistindo sobre a necessidade de uma consulta imediata logo que se encontre no terreno contradições insuperáveis.

\section{RESUMOS}

Os modelos de actividade dos operadores, produzidos em ergonomia, integram cada vez mais uma dimensão subjectiva. As modelisações da actividade dos ergónomos em si mesma não seguiram a mesma evolução. Para facilitar a construção e o desenvolvimento de práticas profissionais, parece necessário modelisar e referenciar no ensino as dimensões subjectivas da actividade do ergónomo.

Los modelos de actividad de los operadores, producidos en ergonomía, integran cada vez más una dimensión subjetiva. Las modelizaciones de la actividad de los ergónomos en sí misma no han seguido la misma evolución. Para facilitar la construcción y el desarrollo de prácticas profesionales, parece necesariomodelizar y referenciar en la enseñanza las dimensiones subjetivas de la actividad del ergónomo.

Les modèles de l'activité des opérateurs, produits en ergonomie, intègrent de plus en plus une dimension subjective. Les modélisations de l'activité des ergonomes eux-mêmes n'ont pas suivi la même évolution. Pour faciliter la construction et le développement des pratiques 
professionnelles, il semble nécessaire de modéliser et de faire référence dans les enseignements aux dimensions subjectives de l'activité de l'ergonome.

The models of operators' activity that are produced in ergonomics, will increasingly include a reference to its subjective dimensions. The models of the ergonomist's activity have not followed the same development. To foster the construction of professional practices, it seems necessary to model and to teach the subjective dimensions of the ergonomist's activity.

\section{ÍNDICE}

Mots-clés: analyse de l'activité, pratique ergonomique, intervention, subjectivité

Palavras-chave: análise da actividade, prática ergonómica, intervenção, subjectividade Palabras claves: análisis de la actividad, práctica ergonómica, intervención, subjetividad Keywords: activity analysis, ergonomic practice, intervention, subjectivity

\section{AUTORES}

\section{FRANÇOIS DANIELLOU}

Université Bordeaux 2 Laboratoire d'Ergonomie des Systèmes Complexes 146, rue Léo-Saignat, Case 55, 33076 Bordeaux Cedex

Francois.Daniellou@ergo.u-bordeaux2.fr 